\title{
The role of inflammation and cardiovascular disease risk on microvascular and macrovascular endothelial function in patients with rheumatoid arthritis: a cross-sectional and longitudinal study
}

Aamer Sandoo ${ }^{1,2^{*}}$, George D Kitas ${ }^{1,2,3}$, Douglas Carroll ${ }^{2}$ and Jet JCS Veldhuijzen van Zanten ${ }^{1,2}$

\begin{abstract}
Introduction: Rheumatoid arthritis (RA) is associated with an increased risk for cardiovascular disease (CVD), and it has been postulated that RA disease-related inflammation contributes to endothelial dysfunction. The aim of the present work was to examine predictors (RA-related and CVD risk factors) and anti-tumor necrosis factor-alpha (anti-TNF- $\alpha$ ) treatment effects on endothelial function in different vascular beds.

Methods: Microvascular endothelial function (laser Doppler imaging with iontophoresis of acetylcholine and sodium-nitroprusside), and macrovascular endothelial function (flow-mediated dilatation and glyceryl-trinitratemediated dilatation) were analyzed in parallel with disease activity. Individual CVD risk factors and global CVD risk were assessed cross-sectionally in 99 unselected RA patients and longitudinally (baseline, 2 weeks, and 3 months) in 23 RA patients commencing anti-TNF- $\alpha$ therapy.

Results: In this cross-sectional study, regression analyses revealed that markers of RA disease-related inflammation were not associated with microvascular or macrovascular endothelium-dependent function $(P>0.05)$; global CVD risk inversely correlated with microvascular endothelium-dependent function $(P<0.01)$ and with macrovascular endothelium-independent function $(P<0.01)$. In the longitudinal study, only microvascular endotheliumdependent function showed an improvement after 2 weeks of anti-TNF- $\alpha$ treatment when compared with baseline $(437 \% \pm 247 \%$ versus $319 \% \pm 217 \% ; P=0.001)$, but no association was evident between change in endothelial function and change in inflammatory markers.

Conclusions: Classical CVD risk may influence endothelial function more than disease-related markers of inflammation in RA. Classical CVD risk factors and anti-TNF- $\alpha$ medication have different effects on microvascular and macrovascular endothelial function, suggesting that combined CVD-prevention approaches may be necessary. Prospective studies examining whether assessments of vascular function are predictive of long-term CV outcomes in RA are required.
\end{abstract}

\section{Introduction}

Rheumatoid arthritis (RA) is a chronic inflammatory musculoskeletal disease that affects $\sim 0.8 \%$ of the adult population. RA also associates with an increased risk for cardiovascular disease (CVD) [1], which is only partially explained by traditional CVD risk factors [2]. The

\footnotetext{
* Correspondence: aamer.sandoo@dgh.nhs.uk

'Department of Rheumatology, Dudley Group NHS Foundation Trust, Pensnett Road, Dudley, DY1 2HQ, UK

Full list of author information is available at the end of the article
}

inflammatory processes of RA and CVD are remarkably similar, suggesting that RA disease-related inflammation might contribute to the excess CVD risk [3].

The vascular endothelium is responsible for maintaining an atheroprotective environment through the release of vasoactive factors, particularly nitric oxide (NO). Noninvasive assessments of peripheral endothelial function in the microcirculation and the macrocirculation may predict adverse cardiovascular outcomes in patients at risk of developing, or with prevalent CVD [4]. Endothelial 
cells differ in structure and phenotype depending on vessel type [5], and heterogeneous responses to in vitro stimulation are displayed in different vascular beds [6], suggesting that endothelial dysfunction (ED) may occur differentially in different vascular beds [6]. Evidence suggests that coronary microvascular disease is apparent in the absence of macrovascular disease in RA [7], and we previously showed that microvascular and macrovascular endothelial function are independent of each other in this population [8]. These findings highlight the importance of assessing endothelial function in different vascular beds.

A number of studies have reported the presence of microvascular and macrovascular ED in RA patients relative to age- and sex-matched healthy controls, which can be improved after treatment with antiinflammatory medications (such as anti-tumor necrosis factor-alpha (antiTNF- $\alpha$ ) [9]. Even though an association between endothelial function and inflammation is often assumed, surprisingly few studies have actually examined this [9]. Cross-sectional studies report equivocal findings; some find an association between inflammatory markers and endothelial function [10], whereas others do not [11]. Longitudinal studies revealed no correlation between changes in inflammatory markers and changes in endothelial function [12,13], and the improvement in microvascular endothelial function after treatment occurred without any change in inflammatory markers [14]. Thus, it remains possible that endothelial function in RA is determined by factors other than systemic inflammation, such as CVD risk factors [9].

The prevalence of classical CVD risk factors is increased in patients with RA [2], and their control is worse [15], compared with that of the general population [16]. At present, no studies have examined associations between classical CVD risk factors in the microcirculation, and only a very few studies have been conducted in the macrocirculation, with inconsistent findings [9]. CVD risk can be calculated by incorporating individual CVD risk factors into algorithms to yield "global" CVD risk scores. Examples of such algorithms are the Framingham Risk Score (FRS) [17] and the Systematic Coronary Risk Evaluation (SCORE) [18]. However, these algorithms do not account for systemic inflammation, whereas the more recent Reynolds risk score does, as it includes C-reactive protein (CRP) in the algorithm. In addition, QRISK2 is the only CVD-risk algorithm that incorporates the presence of RA, as well as socioeconomic status and ethnicity [19]. To our knowledge, the relation between these risk algorithms and microvascular and macrovascular endothelial function has not been investigated in RA.

The objectives of the present studies were to examine determinants of microvascular and macrovascular endothelial function in RA, with a specific focus on diseaserelated markers of inflammation and classical CVD risk.

\section{Materials and methods Cross-sectional study}

Ninety-nine consecutive rheumatoid arthritis (RA) patients were recruited from the rheumatology outpatient clinics of the Dudley Group of Hospitals NHS Trust, United Kingdom. All patients met the retrospective application of the 1987 revised RA criteria of the American College of Rheumatology [20]. Patients were excluded if they had previously confirmed acute coronary syndrome or established cardiovascular disease (CVD).

\section{Longitudinal study}

Twenty-three RA patients from study one, who were about to start anti-TNF- $\alpha$ therapy on clinical indication (UK guidelines), were recruited into a 3-month prospective study. The patients had not previously received any other biologic drugs, including anti-TNF- $\alpha$. Patients were assessed before starting anti-TNF- $\alpha$ (pre-treatment), and 2 weeks and 3 months after initiation of treatment. Fifteen (65\%) of the anti-TNF- $\alpha$ patients were started on $40 \mathrm{mg}$ of adalimumab, six (26\%) on $50 \mathrm{mg}$ of etanercept, and two $(9 \%)$ on infliximab with a dosage of $3 \mathrm{mg} / \mathrm{kg}$. Patients continued treatment with other drugs during the study period, and these included $16(70 \%)$ patients taking methotrexate, one (4\%) taking cyclooxygenase II inhibitors, six (26\%) taking nonsteroidal antiinflammatory drugs, six (26\%) taking prednisolone, four (18\%) taking anti-hypercholesterolemic drugs, and five (22) taking antihypertensive drugs. No change in any of these medications or their doses occurred during the follow-up period. Assessments at 2 weeks and 3 months were performed before receiving the next dose of the antiTNF- $\alpha$ drug.

The study had ethics committee approval, and all participants provided written informed consent.

\section{Study protocol}

Patients reported to a thermoregulated $\left(22^{\circ} \mathrm{C} \pm 0.9^{\circ} \mathrm{C}\right)$ vascular laboratory after a 12-hour overnight fast. They were asked to refrain from exercise 24 hours before the session, and from smoking, 12 hours before the session. For ethical reasons, drug regimens were not interrupted. All participants underwent a detailed clinical examination, and demographic information was collected with a questionnaire. The disease activity score (DAS28) [21] and the Stanford Health Assessment Questionnaire (HAQ) [22] were completed, along with the patients global CVD risk scores. Blood pressure measurements were taken by using an automated blood pressure monitor (Datascope Accutor, Mahwah, NJ, USA). A blood sample was also obtained. 
Patients in the cross-sectional study were assessed at one time point only, whereas patients in the longitudinal study were assessed at pre-treatment baseline, and at 2 weeks and 3 months after treatment with anti-TNF- $\alpha$.

\section{Blood sampling}

The serum was analyzed for total cholesterol, high-density lipoprotein cholesterol (HDL), triglycerides, CRP, and glucose by using a Vitros 5.1 FS Chemistry system. Westergren erythrocyte sedimentation rate (ESR) was measured by using the Starrsed Compact (Mechatronics BV, Hoorn, The Netherlands). Insulin was estimated from serum stored at $-20^{\circ} \mathrm{C}$ by using an Immulite 2500 analyzer (Diagnostic Products Corporation, California, USA). Insulin sensitivity was assessed by calculating the Homeostasis Model Assessment Insulin Resistance (HOMA IR) and Quantitative Insulin Sensitivity Check Index (QUICKI), as previously described [23,24]. All tests were carried out in the routine and research laboratories of Dudley Group NHS Foundation Trust.

\section{Global CVD risk}

Four separate global CVD-risk algorithms were used: FRS [25], SCORE [18], Reynolds risk score [26], and the QRISK2 [19]. These algorithms were calculated at baseline for patients in the cross-sectional and longitudinal studies.

\section{Microvascular endothelial function}

Endothelial function of the microvasculature was assessed non-invasively by using LDI (Moor LDI 2 SIM; Moor Instruments Ltd, Devon, UK) with iontophoresis of $1 \%$ acetylcholine (ACh, endothelium-dependent) and 1\% sodium-nitroprusside (SNP, endothelium-independent) (Sigma Chemical Co, Montvale, NJ, USA) in $2.5 \mathrm{ml}$ solution containing $0.5 \%$ saline, by a single observer (AS). The technique was performed according to previously established guidelines [27] and has been described in detail previously [28]. This technique has an intraobserver coefficient of variation (CV) for ACh and SNP of 6.5\% and $5.9 \%$, respectively, for AS.

\section{Macrovascular endothelial function}

Assessment of macrovascular endothelium-dependent function was performed by using flow-mediated dilatation (FMD) with high-resolution ultrasonography of the brachial artery (Acuson Antares ultrasound system; Siemens PLC, Camberley, UK) according to previously established guidelines [29]. Endothelium-independent responses were examined by administration of a 500- $\mu$ g sublingual glyceryl-trinitrate (GTN) tablet (Alpharma, Barnstaple, UK). The intraobserver CV for the study ultrasonographer (AS) was $10.7 \%$ for FMD and $11.8 \%$ for GTN assessments, respectively. For all vascular tests, endothelial function was expressed as the percentage increase in perfusion or diameter from baseline, and all analysis was carried out offline by AS, who was blinded to the identity of the patient.

\section{Statistical analysis}

Statistical analysis was performed by using SPSS15 (SPSS Inc., Chicago, IL, USA). Variables were tested for normality by the Kolmogorov-Smirnov test. Means and standard deviations (SD) were calculated for normally distributed continuous variables, and proportions for categorical variables. Non-normally distributed data were presented as median $\left(25^{\text {th }}\right.$ to $75^{\text {th }}$ percentile values). Log transformation was performed for positively skewed variables, as appropriate. Variations in degrees of freedom reflect occasionally missing data.

\section{Cross-sectional study}

To assess determinants of vascular function, univariate linear regression (continuous variables) and logistic regression (dichotomous variables) was used. Inflammatory markers, global CVD risk, and CVD risk factors were entered as independent variables, with each measure of vascular function entered separately as the dependent variable. Step-wise multiple regression analysis was conducted to determine independent predictors of endothelial function, and only those variables that came out as significantly associated with endothelial function in the univariate analyses were entered into this analysis. The entry probability was 0.05 , and none of the variables were forced back into the model.

\section{Longitudinal study}

Changes $(\Delta)$ in each parameter of endothelial function, CVD risk factors, and disease-related markers of systemic inflammation were assessed by using three Time (pre-treatment baseline, 2 weeks, and 12 weeks) repeated-measures analysis of variance (ANOVA). Where appropriate, Fisher LSD post hoc tests were used for pair-wise comparisons. Endothelial function did not differ between the three different types of anti-TNF- $\alpha$ treatment at any time point (data not shown); therefore, all treatments were analyzed together. The $\Delta$ in endothelial function and disease-related parameters was calculated by subtracting the pretreatment baseline values from the values obtained at 2 and 12 weeks, respectively. Linear regression was used to examine whether changes in endothelial function were related to changes in disease-related inflammatory markers at each time point.

\section{Results}

\section{Cross-sectional study}

\section{Patient characteristics}

The general and disease-related characteristics for patients in the cross-sectional study are presented in Table 1. Individual CVD risk factors as well as the 
Table 1 General and disease characteristics as well as endothelial function scores for patients in the crosssectional study

\begin{tabular}{|c|c|c|}
\hline & RA patients & Number \\
\hline \multicolumn{3}{|l|}{ General characteristics } \\
\hline Sex female $n(\%)$ & $72(73)$ & 99 \\
\hline \multicolumn{3}{|l|}{ Disease characteristics } \\
\hline RF positive $n(\%)$ & $70(78)$ & 90 \\
\hline Disease duration (years) & $11 \pm 10$ & 74 \\
\hline ESR $(\mathrm{mm} / \mathrm{hr})$ & $17.0(8.8-28.3)$ & 90 \\
\hline CRP (mg/L) & $5.0(2.9-13.50)$ & 93 \\
\hline DAS28 & $3.6 \pm 1.3$ & 93 \\
\hline HAQ & $1.7 \pm .87$ & 95 \\
\hline \multicolumn{3}{|l|}{ RA medications } \\
\hline Methotrexate $n(\%)$ & $60(60)$ & 99 \\
\hline Prednisolone $n(\%)$ & $22(22)$ & 99 \\
\hline NSAIDS n (\%) & $18(18)$ & 99 \\
\hline Cyclooxygenase II inhibitors n (\%) & $11(11)$ & 99 \\
\hline Anti-TNF- $\alpha$ therapy $n(\%)$ & $11(11)$ & 99 \\
\hline \multicolumn{3}{|l|}{ CVD medications } \\
\hline Antihypertensive $n(\%)$ & $25(25)$ & 99 \\
\hline Antihypercholesterolemic $n(\%)$ & $12(12)$ & 99 \\
\hline Beta-blocker n (\%) & $7(7)$ & 99 \\
\hline Calcium channel blocker $n(\%)$ & $5(5)$ & 99 \\
\hline \multicolumn{3}{|l|}{ Microvascular function } \\
\hline Endothelium-dependent (ACh\%) & $236(152-407)$ & 94 \\
\hline Endothelium-independent (SNP\%) & $261(181-384)$ & 94 \\
\hline \multicolumn{3}{|l|}{ Macrovascular function } \\
\hline Endothelium-dependent (FMD\%) & $9.5(4.8-13.5)$ & 96 \\
\hline Endothelium-independent (GTN\%) & $24.0(16.3-30.4)$ & 93 \\
\hline
\end{tabular}

Results are expressed as number (percentage), mean $\pm \mathrm{SD}$, or median $\left(25^{\text {th }}\right.$ to $75^{\text {th }}$ ) percentile, as appropriate. Ach, acetylcholine; CRP, C-reactive protein; CVD, cardiovascular disease; DAS28, disease activity score in 28 joints; ESR, erythrocyte sedimentation rate; FMD, flow-mediated dilatation; GTN, glyceryl trinitrate; $\mathrm{HAQ}$, Health Assessment Questionnaire, NSAID, nonsteroidal antiinflammatory drug; RA, rheumatoid arthritis; RF, rheumatoid factor; TNF, tumor necrosis factor; SNP, sodium nitroprusside.

global CVD risk scores for these patients are shown in Table 2.

\section{Microvascular function}

Endothelium-dependent and endothelium-independent function

Disease-related markers of inflammation

No association was apparent between microvascular endothelium-dependent or endothelium-independent function and any of the inflammatory parameters (ESR, CRP, DAS28, or disease duration) (Table 3).

Individual classical CVD risk factors

Both microvascular endothelium-dependent and endothelium-independent function were inversely correlated with age only (see Tables 3 and 4).

Global CVD risk

The FRS, SCORE, Reynolds risk score, and QRISK2 were all inversely associated with microvascular endothelium-
Table 2 Individual CVD risk factors and global CVD risk scores for patients in the cross-sectional study

\begin{tabular}{|c|c|c|}
\hline & RA patients & Number \\
\hline \multicolumn{3}{|l|}{ Individual CVD risk factors } \\
\hline Age (years) & $56 \pm 12$ & 99 \\
\hline $\mathrm{BMI}\left(\mathrm{kg} / \mathrm{m}^{2}\right)$ & $30 \pm 6$ & 99 \\
\hline $\mathrm{SBP}(\mathrm{mm} \mathrm{Hg})$ & $133 \pm 16$ & 96 \\
\hline $\mathrm{DBP}(\mathrm{mm} \mathrm{Hg})$ & $81 \pm 10$ & 96 \\
\hline Total cholesterol $(\mathrm{mM})$ & $5.1 \pm 1.0$ & 93 \\
\hline $\mathrm{HDL}-\mathrm{C}(\mathrm{m} M)$ & $1.5 \pm 0.3$ & 93 \\
\hline Triglycerides (m) & $1.5 \pm 0.7$ & 93 \\
\hline $\mathrm{TC} / \mathrm{HDL}$ ratio & $3.5 \pm 8.5$ & 93 \\
\hline Glucose (mM) & $4.6(4.3-4.9)$ & 91 \\
\hline Insulin (pM) & $70.4(40.6-105.5)$ & 89 \\
\hline HOMA IR & $2.1(1.1-3.2)$ & 87 \\
\hline QUICKI & $0.35 \pm 0.41$ & 87 \\
\hline \multicolumn{3}{|l|}{ Cigarette-smoking status } \\
\hline Never smoked & $38(42)$ & 91 \\
\hline Previous smokers & $36(40)$ & 91 \\
\hline Current smokers & $17(19)$ & 91 \\
\hline \multicolumn{3}{|l|}{ Global CVD risk scores } \\
\hline Framingham Risk Score & $5(3-10)$ & 87 \\
\hline TC SCORE & $1(0-2)$ & 64 \\
\hline TC/HDL SCORE & $1(0-2)$ & 64 \\
\hline Reynolds Risk Score & $8(3-14)$ & 65 \\
\hline QRISK 2 & $15(7-26)$ & 95 \\
\hline
\end{tabular}

Results are expressed as median ( $25^{\text {th }}$ to $75^{\text {th }}$ percentile values) or mean \pm SD, as appropriate. BMI, body mass index; DBP, diastolic blood pressure; HDL-C, high-density lipoprotein cholesterol; HOMA IR, homeostasis model assessment insulin resistance; QUICKI, quantitative insulin sensitivity check index; SBP, systolic blood pressure; SCORE, systematic coronary risk evaluation; TC, total cholesterol.

dependent function (Table 4), but no associations were evident for microvascular endothelium-independent function.

\section{Macrovascular function}

\section{Endothelium-dependent and endothelium-independent} function

Disease-related markers of inflammation

None of the inflammatory parameters (ESR, CRP, DAS28, or disease duration) was associated with macrovascular endothelium-dependent or endothelium-independent function (Table 3).

Individual classical CVD risk factors

Age was the only individual CVD risk factor associated with both macrovascular endothelium-dependent and endothelium-independent function (see Tables 3 and 4). In addition, resting SBP, insulin, HOMA, and QUICKI were associated with macrovascular endothelium-independent function. A modest association was noted between hypercholesterolemia, hypertension, and macrovascular endothelium-independent function (Tables 3 and 4). Step-wise multiple regression analysis revealed that QUICKI $\left(\beta=0.28 ; R^{2}=0.052 ; P<0.01\right)$ and SBP $(\beta$ $\left.=-0.13 ; R^{2}=0.052 ; P<0.05\right)$ were independently 
Table 3 Linear regression analysis for general and RA disease-related characteristics and endothelial function in RA patients from the cross-sectional study

\begin{tabular}{|c|c|c|c|c|}
\hline & \multicolumn{2}{|l|}{ Microvascular function } & \multicolumn{2}{|c|}{ Macrovascular function } \\
\hline & $\begin{array}{l}\text { Endothelium- } \\
\text { dependent }\end{array}$ & $\begin{array}{l}\text { Endothelium- } \\
\text { independent }\end{array}$ & $\begin{array}{l}\text { Endothelium- } \\
\text { dependent }\end{array}$ & $\begin{array}{l}\text { Endothelium- } \\
\text { independent }\end{array}$ \\
\hline \multicolumn{5}{|l|}{$\begin{array}{l}\text { RA disease-related } \\
\text { characteristics }\end{array}$} \\
\hline Disease duration & $\beta=-0.12, P=0.29$ & $\beta=0.21, P=0.07$ & $\beta=-0.04 P=0.76$ & $\beta=-0.12, P=0.34$ \\
\hline $\log C R P$ & $\beta=-0.61, P=0.05$ & $\beta=0.10, P=0.32$ & $\beta=0.15, P=0.13$ & $\beta=0.00, P=0.97$ \\
\hline LogESR & $\beta=-0.09, P=0.41$ & $\beta=0.18, P=0.10$ & $\beta=-0.01, P=0.95$ & $\beta=-0.08, P=0.46$ \\
\hline DAS28 & $\beta=0.15, P=0.15$ & $\beta=0.02, P=0.84$ & $\beta=0.06, P=0.59$ & $\beta=-0.01, P=0.93$ \\
\hline \multicolumn{5}{|l|}{ General characteristics } \\
\hline Age & $\beta=-0.37, R^{2}=0.135^{c}$ & $\beta=-0.20, R^{2}=0.042^{\mathrm{a}}$ & $\beta=-0.24, R^{2}=0.55^{\mathrm{a}}$ & $\beta=-0.36, R^{2}=0.126^{c}$ \\
\hline BMI & $\beta=0.21, P=0.05$ & $\beta=0.08, P=0.41$ & $\beta=-0.12, P=0.26$ & $\beta=-0.21, P=0.05$ \\
\hline Resting SBP & $\beta=-0.11, P=0.30$ & $\beta=-0.02, P=0.88$ & $\beta=-0.11, P=0.27$ & $\beta=-0.27, R^{2}=0.066^{b}$ \\
\hline Resting DBP & $\beta=0.04, P=0.67$ & $\beta=0.08, P=0.44$ & $\beta=-0.12, P=0.25$ & $\beta=-0.05, P=0.61$ \\
\hline
\end{tabular}

RA disease-related characteristics and general characteristics were entered as independent variables, whereas microvascular and macrovascular endothelial functions were entered as dependent variables in the regression analysis. BMI, body mass index; CRP, C-reactive protein; DAS28, disease activity score in 28 joints; DBP, diastolic blood pressure; ESR, erythrocyte sedimentation rate; SBP, systolic blood pressure. ${ }^{\mathrm{a}} P<0.05$; ${ }^{\mathrm{b}} P<0.01$; ${ }^{\mathrm{C}} P<0.001$. $R^{2}$ value is shown for all significant associations only.

associated with macrovascular endothelium-independent function.

Global CVD risk

Macrovascular endothelium-dependent function was inversely associated with Reynolds risk score and QRISK2, whereas macrovascular endothelium-independent function was associated with FRS, Reynolds risk score, and QRISK2 (Table 4).

\section{Longitudinal study}

Patient characteristics

Patients in the longitudinal study, had an age (mean \pm standard deviation) of $54 \pm 15$ years; 15 (65\%) were female patients; 20 (87\%) were rheumatoid factor positive; and the disease duration was $11 \pm 11$ years.

Eleven (48.8\%) patients were never smokers; seven (30\%), previous smokers; and five (22\%) were current smokers.

\section{Longitudinal effect of anti-TNF- $\alpha$ treatment on disease- related inflammation}

The repeated measures ANOVA revealed an overall effect for morning stiffness, CRP, ESR, DAS28, and HAQ (Table 5). Post hoc analyses revealed that morning stiffness, CRP, DAS28, and HAQ were reduced after 2 weeks and remained low after 12 weeks of treatment. ESR improved 2 weeks after commencing treatment, but

Table 4 Linear and binary regression between classical CVD risk and endothelial function in RA patients from the cross-sectional study

\begin{tabular}{lllll}
\hline & Microvascular function & & Macrovascular function \\
\hline & Endothelium-dependent & Endothelium- independent & Endothelium- dependent & Endothelium- independent \\
\hline $\begin{array}{llll}\text { CVD risk factors } \\
\text { Insulin }\end{array}$ & $\beta=0.13, P=0.23$ & $\beta=0.04, P=0.73$ & $\beta=-0.04, P=0.71$ & $\beta=-0.25, R^{2}=0.065^{\mathrm{a}}$ \\
$\quad$ HOMA & $\beta=0.09, P=0.41$ & $\beta=-0.01, P=0.95$ & $\beta=-0.06, P=0.61$ & $\beta=-0.23, R^{2}=0.052^{\mathrm{a}}$ \\
QUICKI & $\beta=-0.07, P=0.53$ & $\beta=-0.02, P=0.88$ & $\beta=0.11, P=0.30$ & $\beta=0.30, R^{2}=0.095^{\mathrm{b}}$ \\
$\quad$ High cholesterol & $\mathrm{OR}=1.01(0.99-1.00)$ & $\mathrm{OR}=1.00(0.99-1.00)$ & $\mathrm{OR}=1.08(0.99-1.17)$ & $\mathrm{OR}=1.09(1.02-1.17)^{\mathrm{a}}$ \\
Hypertension & $\mathrm{OR}=1.00(1.00-1.00)$ & $\mathrm{OR}=1.00(0.99-1.00)$ & $\mathrm{OR}=1.08(0.99-1.17)$ & $\mathrm{OR}=1.07(1.01-1.14)^{\mathrm{a}}$ \\
$\quad$ Cigarette smoking & $\mathrm{OR}=1.00(1.00-1.00)$ & $\mathrm{OR}=1.00(1.00-1.00)$ & $\mathrm{OR}=1.04(0.97-1.13)$ & $\mathrm{OR}=1.04(0.99-1.10)$ \\
Global CVD risk & & & & $\beta$ \\
FRS & $\beta=-0.26, R^{2}=0.068^{\mathrm{b}}$ & $\beta=-0.18, P=0.09$ & $\beta=-0.12, P=0.26$ & $\beta=-0.32, R^{2}=0.101^{\mathrm{b}}$ \\
TC score & $\beta=-0.28, R^{2}=0.077^{\mathrm{a}}$ & $\beta=-0.17, P=0.18$ & $\beta=-0.23, P=0.08$ & $\beta=-0.14, P=0.30$ \\
TC/HDL score & $\beta=-0.26, R^{2}=0.068^{\mathrm{a}}$ & $\beta=-0.17, P=0.19$ & $\beta=-0.25, P=0.05$ & $\beta=-0.17, P=0.18$ \\
Reynolds Risk Score & $\beta=-0.30, R^{2}=0.088^{\mathrm{a}}$ & $\beta=-0.12, P=0.37$ & $\beta=-0.27, R^{2}=0.072^{\mathrm{a}}$ & $\beta=-0.51, R^{2}=0.259^{\mathrm{b}}$ \\
QRISK 2 & $\beta=-0.33, R^{2}=0.109^{\mathrm{b}}$ & $\beta=-0.19, P=0.08$ & $\beta=-0.22, R^{2}=0.048^{\mathrm{a}}$ & $\beta=-0.51, R^{2}=0.255^{\mathrm{b}}$ \\
\hline
\end{tabular}

CVD risk factors and global CVD risk scores were entered as independent variables, and endothelial functions, as dependent variables in the linear and binary regression analysis. Odds ratio (OR) with 95\% confidence interval is presented for all binary regression analysis. CVD, cardiovascular disease; FRS, Framingham risk score; HDL, high-density lipoprotein; HOMA, homeostasis model assessment; QUICKI, quantitative insulin sensitivity check index; SCORE, systematic coronary risk evaluation; TC, total cholesterol. ${ }^{\mathrm{a}} P<0.05 ;{ }^{\mathrm{b}} P<0.01$. $\mathrm{R}^{2}$ value is shown for all significant associations only. 
Table 5 Disease-related characteristics at baseline, 2 weeks, and 12 weeks

\begin{tabular}{lllll}
\hline & Baseline & 2 weeks & 12 weeks & $\begin{array}{l}\text { Treatment effect } \\
\boldsymbol{F}(\mathbf{2}, \mathbf{2 2})=\end{array}$ \\
\hline Morning stiffness (min) & $116 \pm 75$ & $72 \pm 81^{\mathrm{a}}$ & $55 \pm 83^{\mathrm{a}}$ & $4.33, P=0.02$ \\
CRP $(\mathrm{mg} / \mathrm{L})$ & $10(4-14)$ & $3(2.9-6)^{\mathrm{a}}$ & $5(2.9-10)^{\mathrm{a}}$ & $12.89, P<0.001$ \\
ESR $(\mathrm{mm} / \mathrm{hr})$ & $16(9-34)$ & $10(5-21)^{\mathrm{a}}$ & $17(5-27)$ & $4.98, P=0.01$ \\
DAS28 & $4.17 \pm 0.96$ & $2.74 \pm 1.4^{\mathrm{a}}$ & $2.64 \pm 1.07^{\mathrm{a}}$ & $15.92, P<0.001$ \\
HAQ & $2.1 \pm 0.5$ & $1.3 \pm 0.9^{\mathrm{a}}$ & $1.3 \pm 0.9^{\mathrm{a}}$ & $17.18, P<0.001$ \\
\hline
\end{tabular}

Results are expressed as median $\left(25^{\text {th }}\right.$ to $75^{\text {th }}$ percentile values) or mean \pm standard deviation, as appropriate. ${ }^{\text {a }}$ Different from baseline. CRP, C-reactive protein; DAS28, disease activity score; ESR, erythrocyte sedimentation rate; HAQ, Health Assessment Questionnaire.

was similar to baseline levels at 12 weeks. None of the parameters differed significantly between weeks 2 and 12.

\section{Longitudinal effect of anti-TNF- $\alpha$ treatment on classical CVD risk}

ANOVAs revealed an overall Time effect for HDL cholesterol $(F(2,22)=4.98 ; P<0.01)$, $\operatorname{SBP}(F(2,22)=$ 5.63, $P<0.01)$ and DBP $(F(2,22)=6.99 ; P<0.01)$. Post hoc analysis showed that HDL cholesterol was higher at 2 weeks, but returned to baseline levels by 12 weeks. No change was found in the TC/HDL ratio with anti-TNF- $\alpha$ treatment. SBP and DBP were lower at 2 and 12 weeks relative to baseline. No change was noted in any other parameters.

\section{Longitudinal effect of anti-TNF- $\alpha$ treatment on} microvascular function

ANOVA revealed an overall Time effect for microvascular endothelium-dependent function after treatment (Table 6). Post hoc analysis confirmed that microvascular endothelium-dependent function was increased at 2 weeks, but not different from baseline at 12 weeks. No change in microvascular endothelium-independent function was found after treatment.

\section{Longitudinal effect of anti-TNF- $\alpha$ treatment on} macrovascular function

Both macrovascular endothelium-dependent and endothelium-independent function did not change in response to anti-TNF- $\alpha$ treatment.

Association between changes in inflammation, CVD risk factors, and endothelial function

\section{Microvascular function}

Endothelium-dependent and endothelium-independent function
Linear regression analysis revealed that changes in inflammatory parameters and CVD risk factors were not correlated with change in microvascular endotheliumdependent or endothelium-independent function at 2 weeks or at 12 weeks $(P>0.10)$.

\section{Macrovascular function}

Endothelium-dependent and endothelium-independent function

In the macrovasculature, $\triangle E S R$ and $\triangle D A S 28$ were not related to change in macrovascular endothelium-dependent function at 2 and 12 weeks. However, $\triangle \mathrm{CRP}$ was associated with change in macrovascular endothelium-dependent function at 2 weeks $\left(\beta=0.52 ; R^{2}=0.269 ; P<0.01\right)$, but not at 12 weeks. No associations were seen between change in CVD risk factors and macrovascular endothelium-dependent and -independent function at any time point.

Baseline inflammation and changes in endothelial function Baseline ESR associated with the change in microvascular endothelium-dependent function at 2 weeks $\left(\beta=0.48 ; R^{2}=0.198 ; P<0.05\right)$ and baseline CRP was associated with change in microvascular endothelium-dependent function at 2 weeks $\left(\beta=0.47 ; R^{2}=\right.$ $0.185 ; P<0.05)$ and at 12 weeks $\left(\beta=0.42 ; R^{2}=0.138\right.$; $P<0.05)$. This suggests that those with high levels of inflammation at baseline showed the greatest improvement in microvascular endothelium-dependent function. No other significant correlations emerged from these analyses. The same analyses were repeated for the global CVD risk algorithms, but no associations were apparent.

\section{Discussion}

These findings revealed that, in the cross-sectional study, disease-related markers of systemic inflammation

Table 6 Endothelial function during treatment in the longitudinal study

\begin{tabular}{|c|c|c|c|c|c|}
\hline & Baseline & 2 weeks & 12 weeks & Treatment effect & Degrees of freedom \\
\hline \multicolumn{6}{|l|}{ Microvascular function } \\
\hline Endothelium-dependent (Ach\%) & $314 \pm 214$ & $423 \pm 250^{a}$ & $348 \pm 209^{b}$ & $F=5.09, P=0.01$ & 2,21 \\
\hline Endothelium-independent (SNP\%) & $247 \pm 126$ & $284 \pm 147$ & $261 \pm 152$ & $F=1.18, P=0.32$ & 2,21 \\
\hline \multicolumn{6}{|l|}{ Macrovascular function } \\
\hline Endothelium-dependent (FMD\%) & $9.4 \pm 6.8$ & $12.0 \pm 10.0$ & $12.0 \pm 8.1$ & $F=1.60, P=0.21$ & 2,19 \\
\hline Endothelium-independent (GTN\%) & $22 \pm 7.4$ & $23 \pm 7.2$ & $24 \pm 7.2$ & $F=0.31, P=0.74$ & 2,19 \\
\hline
\end{tabular}

Results are expressed as mean \pm standard deviation. ${ }^{a}$ Different from baseline. ${ }^{b}$ Different from 2 weeks. Ach, acetylcholine; FMD, flow-mediated dilatation; GTN, glyceryl trinitrate-mediated dilatation; SNP, sodium nitroprusside. 
were not associated with microvascular or macrovascular endothelial function in RA. Similarly, changes in inflammatory markers did not consistently relate to change in vascular function after anti-TNF- $\alpha$ treatment, despite a transient improvement in microvascular endothelial function. Global CVD risk, assessed by using several different algorithms, inversely correlated with microvascular endothelium-dependent function and macrovascular endothelium-independent function in the cross-sectional study, and some classical CVD risk factors improved after anti-TNF- $\alpha$ treatment.

RA is characterized by increased systemic inflammation, which has been hypothesized to affect the vasculature and contribute to accelerated atherosclerosis [30]. However, the present findings suggest that systemic markers of inflammation (ESR, CRP, and DAS28) do not relate to endothelial function in two separate vascular beds, in a cross-sectional or longitudinal study. It is worth noting that a trend was seen for an association between microvascular endothelium-dependent function and CRP in the cross-sectional study; however, given the number of associations that were examined, this could be a chance finding. In the longitudinal study, $\triangle C R P$ was associated with change in macrovascular endothelium-dependent function at 2 weeks, but because macrovascular endothelial function did not significantly improve with anti-TNF- $\alpha$ treatment, it is difficult to interpret the implication of this association. In the microvasculature, conflicting associations between endothelial function and disease-related markers of inflammation are reported: one study found an association with TNF- $\alpha$ but not with ESR or CRP [31]; in another, endothelial function was associated with CRP only [10]; and yet another study reported no associations at all [11]. Similarly, a number of studies in the macrovasculature reported no associations between disease-related markers of inflammation and macrovascular endotheliumdependent function [32,33]. Studies that have reported associations present an inconsistent picture, with some finding an association with CRP but not ESR [34], or with DAS28 only [35]. Likewise, the majority of longitudinal studies found no correlations between change in diseaserelated markers of inflammation and change in microvascular and macrovascular endothelial function in response to antiinflammatory treatment, with only one report of an association for macrovascular endothelium-dependent function [9]. Collectively, these findings suggest that the relation between endothelial function and disease-related markers of inflammation may not be as strong as previously suggested.

The transient improvement in microvascular endothelium-dependent function after treatment with anti-TNF$\alpha$ resonates with the findings of a previous study. Komai and colleagues [36] found improvements in microvascular endothelium-dependent function after 2 weeks of treatment with anti-TNF- $\alpha$ when assessing microvascular endothelium-dependent function. In addition, although lower than that at 2 weeks, endothelial function was still increased after 6 weeks of treatment [36]. Therefore, it is possible that after an initial improvement, a gradual decrease in microvascular endothelial function occurs between 6 weeks and 12 weeks. Without a 6 -week assessment in the current study, this must remain speculation. In contrast, Hansel and colleagues [37] observed no change in microvascular endothelium-dependent function at 2 weeks in RA patients; however, these patients exhibited consistently lower disease-related inflammation than did the present cohort. Given that elevated baseline inflammation was associated with greater change in endothelial function, it is possible that change in endothelial function after treatment is unlikely in patients with low disease-related inflammation, and this may explain the seemingly contrasting findings. In line with our findings, in patients with high baseline diseaserelated inflammation, short-term improvement in microvascular endothelial function after anti-inflammatory treatment has been reported [38]. Although no long-term follow-up period was applied, the findings support the notion that, in patients with elevated inflammatory markers, acute improvement in microvascular endothelial function is more likely than longer-term improvements after treatment with anti-TNF- $\alpha$.

Macrovascular endothelium-dependent function did not change in response to 3 months of anti-TNF- $\alpha$ treatment, which is in contrast to previous studies [39-41]. Comparison of the patients included in these studies revealed that average baseline macrovascular endothelium-dependent function was better in the current study than in previous RA patient samples $(9.4 \%$ versus $2.8 \%$ to $7.0 \%$, respectively). Studies that included a healthy control group showed lower baseline macrovascular endothelium-dependent function in the RA patients $[39,42]$. However, in the present study, the baseline macrovascular endothelium-dependent function of the RA patients was similar to that of healthy control participants (data not shown), therefore making an improvement in response to anti-TNF- $\alpha$ unlikely. Thus, it is possible that treatment with anti-TNF- $\alpha$ may have less impact in RA patients who have similar endothelial function than in healthy individuals.

The majority of individual classical CVD risk factors did not associate with endothelium-dependent function in RA in the cross-sectional study, with age being an exception. In the general population, the association between classical CVD risk factors and endothelial function has been well characterized [43]. To our knowledge, no study of RA patients has examined the impact of classical CVD risk factors on microvascular endothelial function, and only a few studies have examined the effects of 
classical CVD risk factors on macrovascular endothelial function $[32,34,44]$. Associations between endotheliumdependent function and lipid levels were present in some [34,44], but not all [32] studies. In the longitudinal study, classical CVD risk factors (SBP, DBP, and HDL cholesterol) improved after reducing RA disease-related inflammation, which is in agreement with other studies [45]. This suggests that inflammation might contribute to the development of classical CVD risk factors in patients with RA. Despite the improvement in classical CVD risk factors with anti-TNF- $\alpha$ therapy, it should be noted that no direct associations were found between the improvement in disease activity and risk factors.

The observation that microvascular but not macrovascular endothelium-dependent function most commonly associated with global CVD risk algorithms and that only microvascular endothelium-dependent function changed after treatment with anti-TNF- $\alpha$ highlights the importance of examining endothelial function in more than one vascular bed. Microvessels make up a much larger proportion of the vasculature than do macrovessels, and may therefore have greater exposure to injurious stimuli [46]. Consequently, it is possible that even small changes in global CVD risk could have a greater effect on microvascular endothelium-dependent function. Therefore, assessments that examine both vascular beds may provide more meaningful clinical information on vascular risk in RA. Even though ED has been associated with clinical end points in patients with cardiovascular disease [4], only one such study with a small sample has reported that high levels of carotid artery intima-media thickness (a subclinical measure of atherosclerosis) are predictive of hard cardiac end points in RA [47]. Therefore, further research is necessary to explore which vascular assessment is the best predictor of cardiac end points in RA patients.

In the macrocirculation, endothelium-independent function was associated with the FRS, Reynolds Risk Score, QRISK 2, insulin resistance, SBP, presence of high cholesterol levels, and hypertension. Evidence indicates that, in healthy individuals with CVD risk factors, abnormalities in endothelium-independent function may occur in the absence of abnormalities in endothelium-dependent function [48]. Further, macrovascular endothelium-independent function, but not macrovascular endotheliumdependent function, was related to a reduction in SBP after 12 and 24 weeks of treatment in patients with hypertension [49]. These findings indicate that CVD risk factors may differentially affect endothelial and smooth muscle cell function, particularly in the macrovasculature. In the current study, endothelium-independent function was significantly lower in patients with hypertension, and some evidence suggests that CVD risk factors like hypertension degrade cyclic guanosine monophosphate (cGMP) [50], a second messenger responsible for the relaxation of vascular smooth muscle cells. In addition, in vitro studies have shown that soluble guanylyl cyclase, an enzyme responsible for activating cGMP, has reduced sensitivity to NO in hypertensive rats [51]. This means that, even if adequate NO is released from the endothelial cells, abnormalities in smooth muscle cell signalling could still lead to a reduced vasodilatory response. Thus, examination of vascular function should include combined assessments of endothelial function and smooth muscle cell function.

The strength of the present work was the inclusion of a large cohort of RA patients at baseline, and the longitudinal assessment of patients newly starting anti-TNF- $\alpha$ treatment. Such a study design allowed the investigation of specific predictors of endothelial function at baseline and over a protracted timescale. Another strength of the study was the extensive characterization of CVD risk by using multiple global CVD risk scores (FRS, TCSCORE, TC:HDL SCORE, Reynolds risk score, and QRISK2), along with comprehensive assessment of CVD risk factors, including HOMA and QUICKI. Unfortunately, the longitudinal study did not have a no-treatment RA control group, for obvious ethical reasons. It is acknowledged that the inclusion of a patient group taking stable medication could have strengthened the design of the study, as it would have allowed exploration of potential fluctuations in endothelial function. However, such a control group is likely to have lower baseline levels of disease-related inflammation, making comparisons to patients with active inflammation difficult. Additional limitations include the inability to examine the effects of other disease-modifying antirheumatic drugs, as well as treatment with corticosteroids. Further research is necessary to establish whether alternative anti-inflammatory medications may exert different effects on endothelial function. Furthermore, the use of other biomarkers of inflammation (for example, CD40, interleukin 6) may help to unravel important pathways that may contribute to vascular pathology in RA. Finally, the etiology of RA has a considerable genetic component in particular; certain human leukocyte antigen alleles appear to associate with worse macrovascular endothelium-dependent function in this group of patients [52]. More recent studies have reported that deletion of certain protective genes (such as CCR5 $\triangle 32$ ) can result in lower macrovascular endothelium-dependent function in RA [53]. Thus, further work examining the genetic influence on endothelial function is required.

\section{Conclusion}

In summary, the present findings suggest that global CVD risk algorithms may be better predictors of vascular health than individual CVD risk factors and systemic markers of disease-related inflammation in patients with RA. Furthermore, classical CVD risk and anti-TNF- $\alpha$ treatment appear to differentially impact microvascular 
and macrovascular endothelial function; therefore, assessments of endothelial function should be performed in both vascular beds. Further studies are needed to confirm whether assessments of vascular function are predictive of long-term CV outcomes in RA.

\begin{abstract}
Abbreviations
Ach: acetylcholine; anti-TNF-a: anti-tumor necrosis factor-alpha; BMI: body mass index; CRP: C-reactive protein; CVD: cardiovascular disease; CV: coefficient of variation; cGMP: cyclic guanosine monophosphate; DAS28: disease activity score in 28 joints; DBP: diastolic blood pressure; ED: endothelial dysfunction; ESR: erythrocyte sedimentation rate; FMD: flowmediated dilatation; FRS: Framingham Risk Score; GTN: glyceryl trinitratemediated dilatation; HAQ: Health Assessment Questionnaire; HDL: highdensity lipoprotein cholesterol; HOMA: homeostasis model assessment; IPAQ: International Physical Activity Questionnaire; LDI: laser Doppler imaging; LDL: low-density lipoprotein cholesterol; NO: nitric oxide; NSAID: nonsteroidal antiinflammatory drug; QUICKI: Quantitative Insulin Sensitivity Check Index; RA: rheumatoid arthritis; SCORE: Systematic Coronary Risk Evaluation; SBP: systolic blood pressure; TC: total cholesterol; TG: triglyceride.
\end{abstract}

\section{Acknowledgements}

The authors thank Dr George Balanos for his help and assistance with the flow-mediated dilatation assessment, and Mrs. Sharon Petford for help with patient recruitment.

\section{Author details}

'Department of Rheumatology, Dudley Group NHS Foundation Trust, Pensnett Road, Dudley, DY1 2HQ, UK. ${ }^{2}$ School of Sport and Exercise Sciences, University of Birmingham, Edgbaston, Birmingham, B15 2TT, UK. ${ }^{3}$ Arthritis Research UK Epidemiology Unit, University of Manchester, Oxford Road, Manchester, M13 9PT, UK.

\section{Authors' contributions}

AS participated in the design of the study, recruited patients, performed the vascular assessments, conducted data analysis, and drafted the manuscript. GK participated in the design of the study, helped with data analysis and in drafting the manuscript. DC participated in the design of the study and helped with data analysis. JVVZ participated in the design of the study, and helped with data analysis and in drafting the manuscript. All authors read and approved the final manuscript.

\section{Competing interests}

The authors declare that they have no competing interests.

Received: 9 January 2012 Revised: 3 April 2012 Accepted: 17 May 2012 Published: 17 May 2012

\section{References}

1. Kitas GD, Erb N: Tackling ischaemic heart disease in rheumatoid arthritis. Rheumatology (Oxford) 2003, 42:607-613.

2. Kitas GD, Gabriel SE: Cardiovascular disease in rheumatoid arthritis: state of the art and future perspectives. Ann Rheum Dis 2011, 70:8-14

3. Stevens RJ, Douglas KM, Saratzis AN, Kitas GD: Inflammation and atherosclerosis in rheumatoid arthritis. Expert Rev Mol Med 2005, 7:1-24.

4. Gokce N, Keaney JF Jr, Hunter LM, Watkins MT, Nedeljkovic ZS, Menzoian JO, Vita JA: Predictive value of noninvasively determined endothelial dysfunction for long-term cardiovascular events in patients with peripheral vascular disease. J Am Coll Cardiol 2003, 41:1769-1775.

5. Ghitescu L, Robert M: Diversity in unity: the biochemical composition of the endothelial cell surface varies between the vascular beds. Microsc Res Tech 2002, 57:381-389.

6. Hill CE, Phillips JK, Sandow SL: Heterogeneous control of blood flow amongst different vascular beds. Med Res Rev 2001, 21:1-60.

7. Banks M, Flint J, Bacon PA, Kitas GD: Rheumatoid arthritis is an independent risk factor for ischaemic heat disease [abstract]. Arthritis Rheum 2000, 43(suppl 9):\$385.
8. Sandoo A, Carroll D, Metsios GS, Kitas GD, Veldhuijzen van Zanten JJ: The association between microvascular and macrovascular endothelial function in patients with rheumatoid arthritis: a cross-sectional study. Arthritis Res Ther 2011, 13:R99.

9. Sandoo A, Veldhuijzen van Zanten JJCS, Metsios GS, Carroll D, Kitas GD: Vascular function and morphology in rheumatoid arthritis: a systematic review. Rheumatology 2011, 50:2125-39.

10. Galarraga B, Khan F, Kumar P, Pullar T, Belch JJ: C-reactive protein: the underlying cause of microvascular dysfunction in rheumatoid arthritis. Rheumatology (Oxford) 2008, 47:1780-1784.

11. Arosio E, De MS, Rigoni A, Prior M, Delva P, Lechi A: Forearm haemodynamics, arterial stiffness and microcirculatory reactivity in rheumatoid arthritis. J Hypertens 2007, 25:1273-1278.

12. Gonzalez-Juanatey C, Llorca J, Sanchez-Andrade A, Garcia-Porrua C, Martin J, Gonzalez-Gay MA: Short-term adalimumab therapy improves endothelial function in patients with rheumatoid arthritis refractory to infliximab. Clin Exp Rheumatol 2006, 24:309-312.

13. Sidiropoulos PI, Siakka P, Pagonidis K, Raptopoulou A, Kritikos H, Tsetis D, Boumpas DT: Sustained improvement of vascular endothelial function during anti-TNFalpha treatment in rheumatoid arthritis patients. Scand J Rheumatol 2009, 38:6-10.

14. Bergholm R, Leirisalo-Repo M, Vehkavaara S, Makimattila S, Taskinen MR, YkiJarvinen $\mathrm{H}$ : Impaired responsiveness to NO in newly diagnosed patients with rheumatoid arthritis. Arterioscler Thromb Vasc Biol 2002, 22:1637-1641.

15. Stavropoulos-Kalinoglou A, Metsios GS, Panoulas VF, Nevill AM, Jamurtas AZ, Koutedakis Y, Kitas GD: Underweight and obese states both associate with worse disease activity and physical function in patients with established rheumatoid arthritis. Clin Rheumatol 2009, 28:439-444.

16. Fletcher B, Berra K, Ades P, Braun LT, Burke LE, Durstine JL, Fair JM, Fletcher GF, Goff D, Hayman LL, Hiatt WR, Miller NH, Krauss R, KrisEtherton P, Stone N, Wilterdink J, Winston M: Managing abnormal blood lipids: a collaborative approach. Circulation 2005, 112:3184-3209.

17. Wilson PW, D'Agostino RB, Levy D, Belanger AM, Silbershatz H, Kannel WB: Prediction of coronary heart disease using risk factor categories. Circulation 1998, 97:1837-1847.

18. Conroy RM, Pyorala K, Fitzgerald AP, Sans S, Menotti A, De BG, De BD, Ducimetiere P, Jousilahti P, Keil U, Njolstad I, Oganov RG, Thomsen T, Tunstall-Pedoe H, Tverdal A, Wedel H, Whincup P, Wilhelmsen L, Graham IM: Estimation of ten-year risk of fatal cardiovascular disease in Europe: the SCORE project. Eur Heart J 2003, 24:987-1003.

19. Hippisley-Cox J, Coupland C, Vinogradova Y, Robson J, Minhas R, Sheikh A Brindle P: Predicting cardiovascular risk in England and Wales: prospective derivation and validation of QRISK2. BMJ 2008, 336:1475-1482.

20. Arnett FC, Edworthy SM, Bloch DA, McShane DJ, Fries JF, Cooper NS, Healey LA, Kaplan SR, Liang MH, Luthra HS: The American Rheumatism Association 1987 revised criteria for the classification of rheumatoid arthritis. Arthritis Rheum 1988, 31:315-324.

21. Prevoo ML, Van't Hof MA, Kuper HH, Van Leeuwen MA, van de Putte LB, van Riel PL: Modified disease activity scores that include twenty-eightjoint counts: development and validation in a prospective longitudinal study of patients with rheumatoid arthritis. Arthritis Rheum 1995, 38:44-48.

22. Kirwan JR, Reeback JS: Stanford Health Assessment Questionnaire modified to assess disability in British patients with rheumatoid arthritis. Br J Rheumatol 1986, 25:206-209.

23. Radikova Z: Assessment of insulin sensitivity/resistance in epidemiological studies. Endocr Regul 2003, 37:189-194.

24. Katz A, Nambi SS, Mather K, Baron AD, Follmann DA, Sullivan G, Quon MJ: Quantitative insulin sensitivity check index: a simple, accurate method for assessing insulin sensitivity in humans. J Clin Endocrinol Metab 2000, 85:2402-2410.

25. Wilson PWF, D'Agostino RB, Levy D, Belanger AM, Silbershatz H, Kannel WB: Prediction of coronary heart disease using risk factor categories. Circulation 1998, 97:1837-1847.

26. Ridker PM, Buring JE, Rifai N, Cook NR: Development and validation of improved algorithms for the assessment of global cardiovascular risk in women: the Reynolds Risk Score. JAMA 2007, 297:611-619.

27. Turner J, Belch JJ, Khan F: Current concepts in assessment of microvascular endothelial function using laser Doppler imaging and iontophoresis. Trends Cardiovasc Med 2008, 18:109-116. 
28. Sandoo A, Veldhuijzen van Zanten JJ, Metsios GS, Carroll D, Kitas GD: The endothelium and its role in regulating vascular tone. Open Cardiovasc Med J 2010, 4:302-312.

29. Corretti MC, Anderson TJ, Benjamin EJ, Celermajer D, Charbonneau F, Creager MA, Deanfield J, Drexler H, Gerhard-Herman M, Herrington D, Vallance P, Vita J, Vogel R: Guidelines for the ultrasound assessment of endothelial-dependent flow-mediated vasodilation of the brachial artery: a report of the International Brachial Artery Reactivity Task Force. J Am Coll Cardiol 2002, 39:257-265.

30. Sattar N, McCarey DW, Capell H, McInnes IB: Explaining how "high-grade" systemic inflammation accelerates vascular risk in rheumatoid arthritis. Circulation 2003, 108:2957-2963.

31. Yki-Jarvinen $H$, Bergholm R, Leirisalo-Repo M: Increased inflammatory activity parallels increased basal nitric oxide production and blunted response to nitric oxide in vivo in rheumatoid arthritis. Ann Rheum Dis 2003, 62:630-634.

32. Kerekes G, Szekanecz Z, Der H, Sandor Z, Lakos G, Muszbek L, Csipo I, Sipka S, Seres I, Paragh G, Kappelmayer J, Szomjak E, Veres K, Szegedi G, Shoenfeld $Y$, Soltesz P: Endothelial dysfunction and atherosclerosis in rheumatoid arthritis: a multiparametric analysis using imaging techniques and laboratory markers of inflammation and autoimmunity. $J$ Rheumatol 2008, 35:398-406.

33. Stamatelopoulos KS, Kitas GD, Papamichael CM, Chryssohoou E, Kyrkou K, Georgiopoulos G, Protogerou A, Panoulas VF, Sandoo A, Tentolouris N, Mavrikakis M, Sfikakis PP: Atherosclerosis in Rheumatoid Arthritis Versus Diabetes: a comparative study. Arterioscler Thromb Vasc Biol 2009, 29:1702-8

34. Vaudo G, Marchesi S, Gerli R, Allegrucci R, Giordano A, Siepi D, Pirro M, Shoenfeld Y, Schillaci G, Mannarino E: Endothelial dysfunction in young patients with rheumatoid arthritis and low disease activity. Ann Rheum Dis 2004, 63:31-35.

35. Pingiotti E, Cipriani P, Marrelli A, Liakouli V, Fratini S, Penco M, Giacomelli R: Surface expression of fractalkine receptor (CX3CR1) on CD4+/CD28 T cells in RA patients and correlation with atherosclerotic damage. Ann N Y Acad Sci 2007, 1107:32-41.

36. Komai N, Morita Y, Sakuta T, Kuwabara A, Kashihara N: Anti-tumor necrosis factor therapy increases serum adiponectin levels with the improvement of endothelial dysfunction in patients with rheumatoid arthritis. Mod Rheumatol 2007, 17:385-390.

37. Hansel S, Lassig G, Pistrosch F, Passauer J: Endothelial dysfunction in young patients with long-term rheumatoid arthritis and low disease activity. Atherosclerosis 2003, 170:177-180.

38. Datta D, Ferrell WR, Sturrock RD, Jadhav ST, Sattar N: Inflammatory suppression rapidly attenuates microvascular dysfunction in rheumatoid arthritis. Atherosclerosis 2007, 192:391-395.

39. Hurlimann D, Forster A, Noll G, Enseleit F, Chenevard R, Distler O, Bechir M, Spieker LE, Neidhart M, Michel BA, Gay RE, Luscher TF, Gay S, Ruschitzka F: Anti-tumor necrosis factor-\{alpha\} treatment improves endothelial function in patients with rheumatoid arthritis. Circulation 2002, 106:2184-2187.

40. Bilsborough W, Keen H, Taylor A, O'Driscoll GJ, Arnolda L, Green DJ: Antitumour necrosis factor-alpha therapy over conventional therapy improves endothelial function in adults with rheumatoid arthritis. Rheumatol Int 2006, 26:1125-1131.

41. Gonzalez-Juanatey C, Testa A, Garcia-Castelo A, Garcia-Porrua C, Llorca J, Gonzalez-Gay MA: Active but transient improvement of endothelial function in rheumatoid arthritis patients undergoing long-term treatment with anti-tumor necrosis factor alpha antibody. Arthritis Rheum 2004, 51:447-450.

42. Bosello S, Santoliquido A, Zoli A, Di CC, Flore R, Tondi P, Ferraccioli G: TNFalpha blockade induces a reversible but transient effect on endothelial dysfunction in patients with long-standing severe rheumatoid arthritis. Clin Rheumatol 2008, 27:833-839.

43. Lerman A, Zeiher AM: Endothelial function: cardiac events. Circulation 2005, 111:363-368

44. Rojas-Villarraga A, Ortega-Hernandez OD, Gomez LF, Pardo AL, LopezGuzmen S, Rango-Ferreira C, Hincapie ME, Juan F, Pineda-Tamayo R, Diaz FJ, Anaya JM: Risk factors associated with different stages of atherosclerosis in Colombian patients with rheumatoid arthritis. Semin Arthritis Rheum 2008, 38:71-82.
45. Boers M, Nurmohamed MT, Doelman CJ, Lard LR, Verhoeven AC, Voskuyl AE, Huizinga TW, van de Stadt RJ, Dijkmans BA, van der LS: Influence of glucocorticoids and disease activity on total and high density lipoprotein cholesterol in patients with rheumatoid arthritis. Ann Rheum Dis 2003, 62:842-845.

46. Stokes KY, Granger DN: The microcirculation: a motor for the systemic inflammatory response and large vessel disease induced by hypercholesterolaemia? J Physiol 2005, 562:647-653.

47. Gonzalez-Juanatey C, Llorca J, Martin J, Gonzalez-Gay MA: carotid intimamedia thickness predicts the development of cardiovascular events in patients with rheumatoid arthritis. Semin Arthritis Rheum 2008, 38:366-71.

48. Adams MR, Robinson J, McCredie R, Seale JP, Sorensen KE, Deanfield JE, Celermajer DS: Smooth muscle dysfunction occurs independently of impaired endothelium-dependent dilation in adults at risk of atherosclerosis. J Am Coll Cardiol 1998, 32:123-127.

49. Ghiadoni L, Magagna A, Kardasz I, Taddei S, Salvetti A: Fixed dose combination of perindopril and indapamide improves peripheral vascular function in essential hypertensive patients. Am J Hypertens 2009, 22:506-512.

50. Yugar-Toledo JC, Ferreira-Melo SE, Consolim-Colombo FM, Irigoyen MC, Coelho OR, Moreno J: Cyclic guanosine monophosphate phosphodiesterase- 5 inhibitor promotes an endothelium NOdependent-like vasodilation in patients with refractory hypertension. Nitric Oxide 2007, 16:315-321.

51. Kojda G, Kottenberg K, Hacker A, Noack E: Alterations of the vascular and the myocardial guanylate cyclase/cGMP-system induced by long-term hypertension in rats. Pharm Acta Helv 1998, 73:27-35.

52. Gonzalez-Juanatey C, Testa A, Garcia-Castelo A, Garcia-Porrua C, Llorca J, Vidan J, Hajeer AH, Ollier WE, Mattey DL, Gonzalez-Gay MA: HLA-DRB1 status affects endothelial function in treated patients with rheumatoid arthritis. Am J Med 2003, 114:647-652.

53. Rodriguez-Rodriguez L, Gonzalez-Juanatey C, Garcia-Bermudez M, VazquezRodriguez TR, Miranda-Filloy JA, Fernandez-Gutierrez B, Llorca J, Martin J, Gonzalez-Gay MA: CCR5Delta32 variant and cardiovascular disease in patients with rheumatoid arthritis: a cohort study. Arthritis Res Ther 2011, 13:R133.

doi:10.1186/ar3847

Cite this article as: Sandoo et al.: The role of inflammation and cardiovascular disease risk on microvascular and macrovascular endothelial function in patients with rheumatoid arthritis: a crosssectional and longitudinal study. Arthritis Research \& Therapy 201214 R117.

\section{Submit your next manuscript to BioMed Central and take full advantage of:}

- Convenient online submission

- Thorough peer review

- No space constraints or color figure charges

- Immediate publication on acceptance

- Inclusion in PubMed, CAS, Scopus and Google Scholar

- Research which is freely available for redistribution

Submit your manuscript at www.biomedcentral.com/submit 